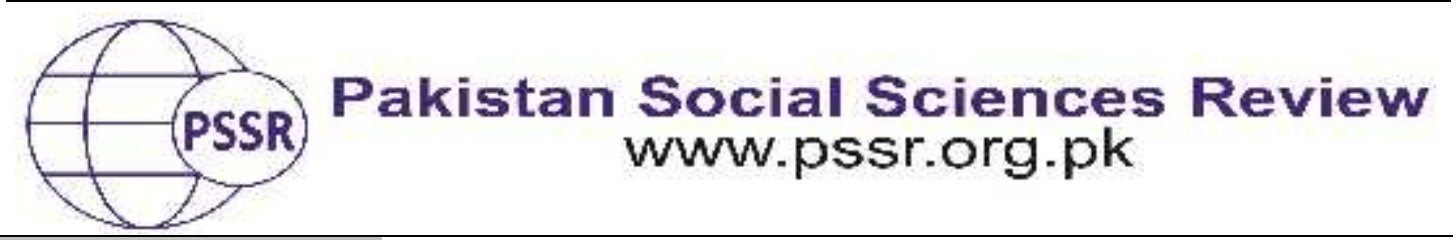

RESEARCH PAPER

\title{
An Overview and Evaluation of Written Corrective Feedback in L2 Writing
}

\author{
Muhammad Ajmal ${ }^{*}$ Nimra Iftikhar $^{2}$ Amna Fajjar ${ }^{3}$
}

1. Assistant Professor, Department of English, Faculty of Language and Literature, University of Lahore, Punjab, Pakistan

2. M. Phil Scholar, Department of English, Faculty of Language and Literature, University of Lahore, Punjab, Pakistan

3. M. Phil Scholar, Department of English, Faculty of Language and Literature, University of Lahore, Punjab, Pakistan

\section{PAPER INFO}

Received:

January 12, 2021

Accepted:

March 01, 2021

Online:

March 15, 2021

Keywords:

Accuracy,

L2 Writing,

Pedagogical

Practices,

Second Language

Written Corrective

Feedback

*Corresponding Author

\section{ABSTRACT}

This article endeavors to revisit the notion of written corrective feedback (WFC) and its effectiveness in language classroom. There are diverse theories in this regard, some are in favour and other are against. In pedagogical perspective, to hone and ameliorate students' writing, teacher's feedback plays a pivotal role. The teacher ought to consider the learners' feelings in regard to feedback, so that they are not demotivated rather feel aplomb and vigour to improve their writing. Truscott (1996) puts a question to the practicability of grammar correction as he thinks that WFC can be harmful for students and he also considers it unnecessary and a waste of time. This study endeavors to address the following questions; a) what are the pedagogical responses towards CWF as a pedagogical approach to ameliorate L2 learners' writing? b) what possible advantages and disadvantages can be identified in WCF? Ferris (1999) negates the notion of Truscott by arguing that WFC should not be renounced as it can help in the improvement of quality of L2 learners' writing. The study concludes in favour of Ferris' idea that asserts WCF as a helpful tool to ameliorate second language writing.

muhammad ajmat

@ell.uol.edu.pk

\section{Introduction}

In 1996, an exceptionally compelling essay entitled "The Case against Grammar Correction in L2 Writing Class", by John Truscott of National Tsing Hua University in Taiwan, appeared in the June version of Language Learning. In his article, Truscott contended that observational examination, second language acquisition (SLA) theory, and pragmatic concerns show written corrective feedback (WCF) in the L2 writing classroom to be both "insufficient" and "unsafe," and that, in this way, it "should be relinquished" (p. 327). Since the time that Truscott initially 
communicated his interests, much ongoing SLA hypothesis and experimental examination have shown the likely viability of WCF in the L2 writing classroom, and have proposed that, whenever attempted wisely, WCF may not involve a significant number of the destructive results estimated by Truscott. A large part of the exploration strategy utilized in these examinations stays dubious, notwithstanding. However, while the general viability of different types of WCF are as yet dubious, WCF can and should assume a restricted part in the L2 writing classroom. How this restricted job should be embraced relies upon numerous components, however the age of the students, the second language capability level of the students, and the nation in which the young learners are examining the entirety of noteworthiness.

Written corrective feedback has been widely researched and discussed in second language writing which is also designated as correcting any written error. We have chosen to investigate CWF as it can be helpful for L2 writers if it is given by teacher with caution and care. Teachers feedback plays a significant role in effective pedagogy .

Several surveys have been conducted which result in favor of Ferris' idea that declares WCF is a helpful tool in the evolution of second language writing but this branch of knowledge does not appreciate the induction by Ferris which states that learners trust grammar correction as well as wants to assume that it's probably true without knowing if it is true or not. The efficacy of various kinds of grammar correction regarding the evolution of second language has been broadly researched by many analysts who evaluated the tests conducted in research facility and lectureroom environment, but hardly anything is found out about the concepts of learners regarding grammar correction in writing. Out of a few existing pieces of research, many of them underestimates the value that Ferris' viewpoint holds by analyzing the effectiveness of grammar correction on basis of students' point of view as it would be too early to devise any conclusion about this topic. To find the real opinion of students regarding the efficacy of grammar correction, more detailed studies are needed in this field.

Truscott's (1996) viewpoint has been highlighted by Ferris (1999) which states "there is no position for semantic rectification in writing subjects and should be deserted" (p.328) and he declares it overrated as well as too early to be accepted. Ferris's viewpoints can be encapsulated in the following prospects: the surveys that were conducted to find the opinions of students resulted in favor of significance of grammar correction; professors think that the linguistic errors of students are very disturbing and annoying and they also affect the performance metric of their papers; the linguistic difficulties of students should not be disregarded by the writing instructors; the necessity of making the editing expertise better, will not be taken solemnly by learners in case of absence of any feedback and the students will not acknowledge the significance of editing even when they perceive its importance. 


\section{Literature Review}

For understanding the tendency of research regarding the benefits of feedback, it is crucial to analyze several approaches that different researchers have used to explain this mechanism and its efficacy in the learning process. The current study will determine an anecdote that will bring about several definitions of feedback and will feature all the similarities and discrepancies among various analysts.

Feedback was explained as "either of a several processes utilized in revealing to a student either their didactic answer is wrong or right" (p. 211) by Kulhavy. Such as, a clear precedent in order to demonstrate that explanation of feedback will be by giving a learner an accurate response. Kulhavy (1977) suggested besides explaining the description regarding feedback, that the efficacy or quality concerning the feedback are affected with "research availability" as well, which is explained as the accessibility of all the useful details for the learning to happen. More specifically, with less "research availability" the learning is inclined to be prosperous. Because the less availability of research data compels a learner to reach out for more information and knowledge find out the right answers to their questions rather than simply plagiarizing them. For instance, if we simply provide the right answer to the students then the learning might be less fruitful in comparison to the learning schemes where students have to search for all the necessary data and information. This response was further validated through Bangert-Drowns et al. (1991), whose proposal was "research availability" significantly affected all outcomes regarding feedback assistance. In case of less "research availability," learners reach out to get more information and knowledge which reverts to the cognitive theory of learning which explained that learning becomes more efficient when the students interact with their surroundings dynamically.

Many researchers have suggested comprehensive explanations of feedback just like the one proposed by Kulhavy (1977). All such explanations describe feedback as acknowledging the students about their actions to guide them to either fortify the right answers or to find a substitution for the few that are wrong ones. (Hattie et al.,1996). It was declared by Kulhavy (1977) that "a lucrative guidance forever contains feedback regarding performance" (p. 3). Simply put, while providing the feedback it is necessary to list all the possible steps to be taken to improve the execution. As asserted by Hattie et al. (1996), for improvement in the performance of students feedback is crucial and should be broadly used in education. He further supported his argument by giving an example of homework assignments. He argued that homework with feedback is beneficial as compared to homework without any feedback about their performance. As explained by Hattie et al. (1996), the mere helpful yet beneficial tool is feedback, if the students are acknowledged about the steps regarding the betterment in their execution.

According to Stock\& Kulhavy (1989), the classification of feedback includes authentication as well as illustration. Authentication has been explained as merely 
an attestation of right or wrong answers, while illustration is explained as a process that presents all the steps to guide the students to find the right answers. As claimed by Hattie et al.(1996), both these types of information are mandatory as several analysts accept the fact regarding these two definitions are crucial for feedback to be efficient. In simple terms, feedback should not only contain the confirmation of right or wrong answers but there should also be all the steps to direct them to find the right answers.

\section{Feedback as an Instructional Tool}

There is an immense research on the phenomenon of feedback. As devised by Pressey, an experimenting gadget in 1926, that gives the learners a prompt retaliation about the accuracy of their answers. Trowbridge and Carson regulated an analysis in 1932 to observe the efficacy of feedback. In their experiment, they covered the eyes of their subjects with a piece of cloth and asked them to draw four inches long lines. All individuals were divided into groups, an experimental one in which feedback was given to subjects and a control one where no feedback was provided. Both the groups were given 100 tries for the accomplishment of their task. The analysts discovered that the subjects in the experimental group had a positive impact on their performance by the passage of time as compared to the control group which did not show any refinement. The two of these researches indicate that even 80 years ago, the analysts were trying to find out whether providing learners with feedback helps them in the refinement of their performance or not.

It is necessary to grasp the history of feedback for a better understanding of all the theories regarding feedback, that altered by the passage of time from behavioral theory into cognitive approach. As observed by Bangert-Drowns and Kozma (1987), many people who advocates behaviorism regarded assessment as stimulus-response theory, in which main motive of assessment has been to encourage an individual for restating the right answers. This concept provided the core for programmed learning. The cognitive theory of learning, which progressed in retaliation to behaviorist theory, is beyond just a stimulus-response theory. The supporters of cognitive theory perceive feedback as a mechanism that helps learners by educating them about all the ways to manage and direct their learning on by themselves, as stated by Bangert-Drowns et al., 1991. Cognitive theory of learning then began perceiving student like engaging participator of acquainting procedure. Effects of providing feedback to learners in their acquainting procedure is an actual difference between the cognitive as well as behaviorist theories. Students are perceived as engaging participators by many advocates of cognitive theory in acquainting procedure, meanwhile the students have been perceived non-resistant recipients in acquainting procedure by several supporters of behaviourism. 


\section{Feedback and Its Role in Second Language Acquisition}

According to Lightbown \& Spada 1994, a responsive manifestation regarding focus on form approach, feedback is declared as a beneficial tool regarding assistance in observing thus valuable in foreign language learning. Over the past three decades, the feedback has gone through a considerable amount of research in regards to its clarity and obliqueness, its benefits regarding second language accretion, the kind of verification it gives, and essentially, the learning process it generates. A comprehensive discourse on feedback starts with looking into its categories.

Various kinds of errors ought to be dealt in a different way, researchers have moved away from wide adjustment of each mistake (what is named "exhaustive" blunder revision) and directed their concentration toward centered rectification of blunder, specifically botches in the utilization of distinct and inconclusive articles. In the vast majority of the cases, having given criticism on exceptional gatherings of mistakes, the educators caused more victorious understudy advancements (Ferris, 2001). They called attention to that where the blunder amendment isn't centered, however far reaching, almost certainly, understudies should get a lot of rectification on a huge bit of composing and won't have the option to check every one of their mistakes. An examination completed by Karimi and Fotovatnia (2010) has uncovered that composed restorative input is of wide instructive worth, and zeroed in CF and Unfocused CF can similarly add to the syntactic exactness in L2 composing. Another investigation directed by Farrokhi (2011) demonstrated zeroed

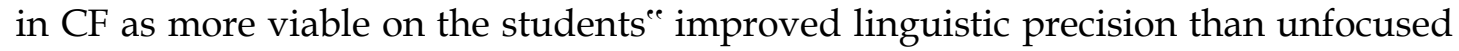
CF regarding instructional method. In an examination completed by Frear (2010), having thought about the differential impacts zeroed in direct Corrective input on the students ${ }^{\text {e }}$ utilization of past tense to unfocused direct Corrective criticism and another gathering accepting no input, the scientist demonstrated that no distinction existed among the three gatherings. It was found, at any rate, that the test bunches showed improvement over the gathering accepting no input as far as their exhibition on second composition. Farrokhi (2011) additionally led an examination on the viability of zeroed in and unfocused roundabout input on the utilization of straightforward past tense in L2 composing. There were three gatherings of understudies, centered gathering, unfocused gathering, and control gathering. Doing the examination, the specialists concocted no measurably critical contrast among the three groups.

The research on feedback in second language accretion went through a progression that was akin to feedback (e.g., Henderickson, 1978). Henderickson (1978) explains that language procurement analysts researched for decades to find some persuasive ways for acknowledging the learner misconceptions. The history of second language learning has moved forward from old methods of learning a foreign language when mistakes were highlighted inadequately. Now mistakes are perceived as a fragment of acquainting procedure which shows that student has 
beenprogressing to make up a new language structure. The common purpose amid the analysts is forever focusing over the correction of error inseveral lecture-rooms as well as struggling with regard to find out some methods in order to retort the of a learner. Henderickson (1978) composed an overall sketch of the research regarding the error correction method and he also proposed that the learners should find the mistakes and should be more engaged in error treatment method, which can assist them in return to continue to get new knowledge in their memory.

There are still several different perceptions regarding error treatments and it seems that many analysts accept the fact that there should be more than one way to correct the errors, although, it is still ambiguous that which kind of feedback from the teacher shows more improvement in learner's uptake. It also introduces a sketch of different researches that have been done in this field by highlighting the disparities and analogies among the discoveries regarding the efficacy of feedback in a foreign language classroom.According to (Ellis et al., 2006), corrective feedback is feedback to the observation of a learner that includes the error. Just as wrongdoing, mistakes can be ignored and their effects get better off, but its existence is anticipated and the primary course of action of getting better off is to reduce the time between the wrong answers and the demonstration of the right model once again (p. 56).

\section{FEEDBACK AND CLASSIFICATION}

According to Ellis et al. (2006), analysts of L2 learning differentiate feedback on basis of its clarity. In the case of indirect feedback, the mistakes are not mentioned, while in the case of direct types of feedback, the errors are indicated.The kinds of feedback that are often repeated are implicit as defined by Long (1996):

Formulating all or few parts of learner's former observation in different ways in which one or more non-target like (semantic, lexical, etc.) elements are restored

by an analogous target language form, whereas the center of attention of dialogists is the meaning but notthe language as a target throughout the

exchange(p.2).Although, this binary categorization of feedback can be troublesome. The study reveals that relying upon circumstances (cf. Sheen, 2004) along with the properties of restates (such as linguistic targets, length, and many changes), modifications can be direct and clear, for instance, bu adding intonation and stress (Egi, 2007a).

According to various researchers, an explicit kind of feedback can have many types. Explicit feedback can be fashioned as clear and direct rectification as asserted by Ellis et al. (2006), where it is crystal clear that learner made an incorrect observation, or metalinguistic feedback, explained by Lyster and Ranta, 1997 "in response to utterance of learner, all the remarks, queries, or all the data " ( p. 47).

Explicit feedback has been enlisted by several researchers in different manners. Take Carroll (2001) and DeKeyser (1993) as an example, who differentiated, clear and direct response which includes guidelines about the 
description of the error, from the explicit feedback that gives intricate metalinguistic understanding. (Sheen, 2007).

The accuracy of juxtaposing the outcomes of response according to the stages of clarity as examined by Lyster (2002), on basis of his finding that it is renovation which is conclusion of significant causes instead of arising out of clarity which helps in advancement of foreign language. Redesign was also differentiated from the causes by Lyster, that contains descriptive petitions, metalinguistic indications, reiterations, and eradication of the accurate form. He draws a clear picture of differentiation on basis of that idea, while redesign gives learners the object shapes, cues might occupy the students at a comprehensive phase concerning transformation as the students are needed to bring back objectives on their own. The subsequent table gives a deeper explanation of classification of feedback. Corrective feedback has been categorized into seven classes by Lyster and Ranta(1997): as defined in the table below:

\begin{tabular}{ll}
\hline \multicolumn{1}{c}{ Kinds of WCF } & \multicolumn{1}{c}{ Definitions } \\
\hline $\begin{array}{l}\text { Metalinguistic } \\
\text { feedback }\end{array}$ & $\begin{array}{l}\text { This is a kind of feedback in which the instructor guides the } \\
\text { learner about his mistakes, but does not tell him/her the right } \\
\text { way to find out. For example; can you spot the error? So } \\
\text { metalinguistic feedback is a sort of unclear and indirect } \\
\text { information about the errors. }\end{array}$ \\
\hline Explicit & $\begin{array}{l}\text { The kind of feedback in which the instructor gives the learner a } \\
\text { response of accurate answers and provides them the information } \\
\text { about the incorrect answers. }\end{array}$ \\
\hline Elicitation & $\begin{array}{l}\text { Feedback where the instructor deliberately stops the learner and } \\
\text { guides him/her about the errors. The teacher may also ask } \\
\text { questions to the learner to bring about the correct form and help } \\
\text { them in finding a better way to formulate the responses. }\end{array}$ \\
\hline Recast & $\begin{array}{l}\text { The kind of feedback in which the teacher transcribes the } \\
\text { mistakes of students and omits them out without providing } \\
\text { accurate answers }\end{array}$ \\
\hline Translation & $\begin{array}{l}\text { The type of feedback in which the teacher provides detailed } \\
\text { correction processes. }\end{array}$ \\
\hline Repetition & $\begin{array}{l}\text { The feedback in which the instructor highlights the mistakes of } \\
\text { the student by emphasizing the errors. }\end{array}$ \\
\hline Clarification & $\begin{array}{l}\text { Feedback in which the teacher highlights the student's errors that } \\
\text { were not acknowledged and asks the student to formulate it } \\
\text { differently. }\end{array}$ \\
\hline
\end{tabular}

\section{The Role of Output and Input in SLA}

A discussion has been in progress regarding the part played by the positive and negative evidence and the impact concerning output as well as input on learning foreign language. 


\section{Definition of Types of Evidence}

A common agreement exists among both the L1 and L2 literature which states that students of language experience two kinds of input such as negative and positive evidence. Gass (2003) explains positive evidence as an input comprising of a collection of semantic sentences, speech samples that are feasible for the written and spoken language. These speech samples are a clear and direct way for learners which can help them in forming a linguistic hypothesis. For acquainting both L1 and L2, positive evidence has been perceived asa basic demand (Gass 2003).

On the contrary, a kind of input that is given to such learners who are concerned regarding the inaccuracy of an utterance is negative evidence. This can be in the form of clear/direct and unclear/indirect information. Based on the taxonomy by Long and Robinson (1998), there are two types of negative evidence. The first being the pre-empt that arises before any definite error like the one in a classroom context, also called reactive or pre-planned and if it is reactive then it could be implicit or explicit. Explicit negative evidence is an obvious correction. On the other hand, implicit negative evidence can either be a communication failure or a restate. Long and Robinson keep on stressing on defining recasts as implicit negative evidence, meanwhile, several other professors debate that this might not certainly be true in all didactic situations (Lyster \& Mori, 2006; Ellis \& Sheen, 2006).

The fact is comprehensible which states that positive feedback is certainly obligatory for learning since one should be aware of the series of grammatical sentences for learning to happen. Although over the past three decagons in L2 learning, the part played by negative evidence has been a questionable matter. Development of the verification along with input vs output discussion is presented in details as follows.

\section{Student Uptake/Repair}

Besides few different kinds of feedback in second language learning, term "uptake" is explained in literature as reaction from the learner to the feedback given to him after the occurrence of an error. Meanwhile, the term "repair" is explained as the efficacy of specific feedback. The two of these terms will be discussed in this segment. For a very long time, the term uptake has been a topic of discussion for many researchers including Lyster and Ranta (1997), Chaudron (1977), Ellis, Basturkmen, and Loewen (2001) who have done many a lot of research. An initial analysts who came up with a phrase uptake was Chaudron (1977) who proposed that, efficacy regarding reaction can be evaluated by counting how frequently a learner responds to the reaction along with accurate answers. Uptake was then explained by Lyter and Ranta (1997) as a quick reaction of a leaner to the feedback of the instructor and the response regarding the information of the student's presentation. Chaudron's explanation of uptake was further explained by Lyster and Ranta (1997), splitting the uptake into further two classes, one being the "repair" and the other one "needs repair" (p.49). Lyster and Ranta (1997) explained the term repair as a beneficial correction of a wrong response in reaction to the feedback of 
the instructor. On the contrary, the term needs repair means an unsuccessful response of a learner to the feedback of the teacher regarding the correction of a wrong response. Needs repair can bring about the need for another feedback in aid of a successful learner restoration.

Repair was further categorized into two classes by Lyster and Ranta (1997), one being the self-initiated and the second one being other-initiated repair. Otherinitiated repair generally arises by providing the student with some kind of feedback. In case of any mistake, an instructor or fellow learners can also give a feedback. The explanation of Lyster and Ranta regarding uptake of learner, particularly needs repair and repair, which were opted with regards to utilization in research as they contain a comprehensive and detailed classification of this kind of reaction of learner.

In foreign language acquisition procedure uptake plays an integral part as well as noticed by Loewen (2002) that a lot of analysts were curious about analyzing uptake as well as associating uptake with procedure of acquainting a foreign language. Meanwhile, Ellis et al. (2001) advocated this explanation as well with a proposal in which he affixed uptake as determinants of procedure of foreign language acquisition. In L2 acquisition, the part played by feedback has been a reliable one in L2 learning and several other fields of studies which include linguistics (Schwartz, 1993; White, 1987) psychology (De Bot, 1996), and cognitive science (DeKeyser, 1998, 2001). The perspective of researchers differs a lot in regards to the kinds of evidence given by feedback, their categorization, along their part played regarding the progress concerning particular territories of L2.

There are a variety of different theoretical viewpoints under these various perceptions regarding the part played by negative and positive evidence (Gass, 2003) in the L2 learning process, which represents the educational background of the researcher and their research conditions. In starting of this research the semantic perceptions have been scrutinized in deliberation regarding process of L2 learning in relation with analysis of assessment. A controversy regarding the categorization of feedback as well as its efficiency concerning L2 acquisition mechanism has been raised with regards the review above. A debate concerning various theories and hypotheses has eventually lead the study to the to the point where the the part played by restorative response in L2 acquisition has been introduced.

\section{Krashen's Input Hypothesis}

All the conventional classroom interference like semantic coaching as well as fallacy rectification and the part played by negative evidence in language acquisition were dismissed with an input hypothesis by Krashen $(1982,1985)$. He asserted it as well that a comprehensible input to learn language is basic requirement of every student of the second language; also that there a distinction between the knowledge of deliberately acquired dialect and heedlessly learned dialect; and that the only kind 
of apprehension that can prosper is in instinctive dialect utilization and that no synergy can exists between "acquisition" \& "learning".

Krashen's input hypothesis was denounced by several other theories which both reiterate the part played by input as well as positive evidence in acquisition of language. As highlighted by White (1987), significance of response specifically for the demonstration of inability concerning learner's interlanguage structure. She also highlighted the inadequacy of positive evidence in learning procedure of a foreign language, further it was suggested by her that in-coherency of input was brought about from the negative evidence which turns into the force for students which identifies that the rule system is insufficient.

\section{Swain's Output Hypothesis}

The classical belief that in learning second language input is the mere obligation was protested by output hypothesis of Swain $(1985,1995)$. As well as he asserted that the ending result of acquainting a foreign dialect is output which contains almost no value in process of learning a dialect (e.g., Krashen 1985). Swain discovered out of her analysis of knowledge in the French pre occupational circumstances that regardless of spending several years for discovering the extensively coherent guidance in informative lecture-rooms, learners have semantic deficiency regarding syntax and morphology (Harley \& Swain, 1984; Light \& Spada, 1994). Hence, Swain asserted that for students to make a response which is semantic as well as free of mistakes, merely an input that is understandable, is not sufficient. Moreover, in moments where students feel reluctant and cannot communicate properly, are the occasions they want to be encouraged to give a definite as well as correct outcome, and that is the only purpose for advocating output as a measure to better the process during L2 learning

Generally, in acquainting a foreign language the significance of production can be assembled with regards to the cognitive operations brought about by output and the effective involvement of the learner. Meanwhile, Gass, Mackey, and Pica (1998), specified that getting involved in grammatical processing is crucial for learners to endeavor words certainty rather than the understanding of interrogator input that plays a central role in learning mechanism. As well as, it's advocated that making the object dialect might be presented like as present by Swain, 1985, " the reason for students to be careful regarding their explanation to communicate properly their designed message" (p.249). Moreover, corrective feedback is given major emphasis by Swain, where actually correlating insufficiency of a response along with insufficiency concerning a forced productivity regarding the disappointing execution of learners in semantic reliability captivating lecture-rooms.

Swain polished her interpretation since comprehensible output or output hypothesis was initially suggested, as well as she stated the four objectives of output. Firstly, the role played by output is in eloquence that gives the student several favorable circumstances for establishing an accelerated approach to their current L2 understanding in certain utilization of syntax during purposeful situations. 
Secondly, the role of output in examining a hypothesis is with regarding to generating such an output that students are capable of forming as well examining the hypothesis regarding the semantic correctness as well as certainty concerning the responses with regards to reaction to questioner's assessment. Thirdly, the role played by output is metalinguistic and students think deeply about their target language use. For analyzing their utilization of a foreign dialect, output mechanisms cab very helpful as well as in adjoining their understanding of linguistics regarding which they possess an explanatory insight. The knowledge of rules and applications might augment through observing the dialect regarding a subject framework. The output then represents an important function particularly, in generating the aimed dialect, "a disparity is observed by the learners between what is their need to assert and what it is that they are able to convey, which helps them in determining what they are familiar with and with what they are not" (Swain, 1995, pp. 125-126). Students are then convinced to concentrate carefully on appropriate instructions in input with the acknowledgment of errors, that will bring about the interlanguage progress in their performance.

Briefly, the output hypothesis of Swain asserts that output can benefit language learning under fixed conditions, by approving the learners to call for response of interrogators as well as instructors who educates the learners about certainty as well as development concerning the interlanguage responses, moreover acknowledging the learners to reach out more than grammatical refinement to linguistic refinement. The crucial part of the basic procedure of acquainting second language is linguistic refinement.

\section{Attention, Awareness, and the Noticing Hypothesis}

In applied linguistics, the sole disputed concern has been indicated by discussion on output and input along with negative and positive evidence, regarding part played by unconscious and conscious mechanisms in second language acquisition. Meanwhile, many think that if students try to generate correct forms and utilize them in proper situations, then proper comprehension of part played by target dialect is important. Considering this, few causes of mistakes include not having a complete comprehension of target dialect, overlooking the rules, as well being less attentive to them (Schmidt, 1990). On the other hand, many strongly think learning a new language is instinctive mechanism (e.g., Krashen, 1985).

\section{Schmidt's Noticing Hypothesis}

Taking out data arising out of research done by Frota as well as Schmidt (1986), Schmidt erected that the two narratives mentioned before cannot describe his encounter with acquainting Portuguese. It was pointed out in his notes that all the patterns that were drew, were observed by him about what folks told him. He erected this as well that all the verbs he was directed about, didn't make certain that they might occur in output. Moreover, it was also erected by him that all the speech 
forms which were pointed out him, were the ones that integrated to consequent output of a dialect. It was also claimed by Schmidt (1990) that in this field of study, this research is effective one among the majors in the second language acquisition.

Two of the principal topic of discussion was heightened in cognitive psychology, as explained in the noticing hypothesis by Schmidt. Those two crucial topics were awareness and attention, which were perceived as basic reasons of formation of advanced information as well as for alternation of already existing knowledge. Awareness and attention both are topics that include discrete view, are somehow linked but are not equivalent.

Schmidt (1990) asserts that acknowledgement is an intuitive encounter as well as is usually associated with alertness. Schmidt defies any innate acquaintance of information in his primary work by refusing any separation among acknowledgement and acquainting new information. The two stages of consciousness including one at point of comprehension and the other one at point of detecting, were distinguished by Schmidt. Hence, Schmidt asserted that consciousness is very important at point of detecting for acquainting a dialect, while consciousness is not mandatory at point of comprehension in second language acquisition process.

\section{The Interaction Hypothesis}

Those who support rewording mostly choose the interaction hypotheses of Long (1996), in which he asserted that the principal cause of dialect input is gestures during conversation including clarification as well as recast appeal, which facilitates the learners to debate and consequently assisting the process of language development. The interaction hypothesis of Long (1996) emerged from the research by Krashen when he asserted that in acquainting second language an understandable input is mandatory. As well as, Long derived idea from work of Hatch (1978) in which he asserted that for successful progression in grammar debate is a significant element. Considering this, when students experience conversational barriers while debating about the message, they suffer from comprehending the response from their instructor. Meanwhile, the instructor has to grasp onto the dialect which gives rise to adjustment in grammar but in purposeful framework.

In a modernized statement of interaction hypothesis by Long (1996), the part played by negotiation interaction has been highlighted which brings about negative feedback in acquainting second dialect, "in second language progression, negative feedback can useful which might be gained from strategic discussion" (p. 414). With regards to feedback approach, rewording has extreme importance in it, as it gives both negative and positive confirmation by correlating the incorrect and correct responses. 


\section{Principles of Universal Grammar}

By the end of the 20th century, learning a dialect began dropping confusions regarding the behaviorist model of teaching and language acquisition and orderly grammar direction's importance as well as its efficiency and response for correction in L2 acquisition and mother tongue. Strong assertions against a focus on form are proposed by Krashen (1985), Hammond (1988) and Schwartz (1993). As Hammond asserts that rectifying the mistakes is insignificant in accelerating L2 learning. Undoubtedly, the professionals of linguistics suppose that rectifying the errors could be catastrophic and keep it view consequently it is refrained. Also they believe that rectification might trigger strainer which refines the learner's attitudes that affect the relative success through lifting the amount of angst of the learners, consequently averting student from acquainting conversational skills. Advocates of this perception generally believe that learning first and second dialect is controlled with fundamentals of grammar as well as semantic framework is learned through fix arrangement, despite the amount of rectifying response or course of commandments.

\section{Conclusion}

This study revisited the notion of written corrective feedback (WFC) and its effectiveness in language classroom and discussed diverse theories in this regard, some are in favour and other are against. In pedagogical perspective, to hone and ameliorate students' writing, teacher's feedback plays a pivotal role. The teacher ought to consider the learners' feelings in regard to feedback, so that they are not demotivated rather feel aplomb and vigour to improve their writing. Despite that feedback is considered a response from teachers from didactic perspective. Ellis (2007) asserts that the circumstantial as well as interactive description of feedback should be investigated in analysis or research which perceives feedback in the light of related literature. In the current research, feedback comprises a diversity of approaches that range from the most implicit to the most explicit end of the continuity. A functioning explanation regarding feedback in the current research is response of instructor that highlights the inaccuracy of the expression of a learner. 


\section{References}

Bitchener, J. (2008). Evidence in support of written corrective feedback. Journal of second language writing, 17, 102-118.

Carroll, S. (2001). Input and evidence: The raw material of second language acquisition. Philadelphia: John Benjamins.

Chandler, J. (2003). The efficacy of various kinds of error feedback for improvement in the accuracy and fluency of L2 student writing. Journal of Second Language Writing,12, 267-296.

Chaudron, C. (1977). A descriptive model of discourse in the corrective treatment of learners' errors. Language Learning, 27, 29-46.

Chaudron, C. (1988). Second language classrooms. Cambridge: Cambridge University Press.

De Bot, K. (1996). The psycholinguistics of the output hypothesis. Language Learning, 46, 529-555.

Dekeyser, R. (1993). The effect of error-correction on L2 grammar knowledge and oral proficiency. Modern Language Journal, 77, 501-514.

Dekeyser, R. (1998). Beyond focus on form: Cognitive perspective on learning and practicing second language grammar. In C. Doughty, \&amp; J. Williams (Eds.), Focus on form in classroom second language acquisition (pp. 42-63). New York: Cambridge University Press.

Dekeyser, R. (2001). Automaticity and automatization. In P. Robinson (Ed.),Cognition and second language instruction (pp. 125-151). New York: Cambridge University Press.

Ellis, R. (2009). Corrective Feedback and Teacher Development. L2 Journal, an electronic refereed. Journal for foreign and second language educators (1). pp. 3-18

Farrokhi, F., \& Sattarpour, S. (2011). The Effects of Focused and Unfocused Written Corrective Feedback on Grammatical Accuracy of Iranian EFL Learners. Theory and Practice in Language Studies, 1(12), 1797-1803.

Ferris, D. R., \& Barrie, R. (2001). Error feedback in L2 writing classes .How explicit does it need to be? Journal of Second Language Writing, 10, 161-184

Frear, D. (2010). The Effect of Focused and Unfocused Direct Written Corrective Feedback on a New Piece of Writing, College English: Issues and Trends, 3, 59-71.

Gannon, P. (1985). assessing writing principles and practice of marking written English, Edward Arnold, and Caulfield East, Australia. 
Hammond, R. M. (1988). Accuracy versus Communicative Competency: The Acquisition of Grammar in the Second Language Classroom. Hispania, 71， 408-417.

Harley, B., \&amp; Swain, M. (1984). The inter language of immersion students and its implications for second language teaching. Edinburgh University Press.

Hatch, E. (1978). Discourse analysis and second language acquisition. In E. Hatch(Ed.), Second language acquisition: A book of readings (pp. 401-475). Rowley, MA: Newbury House.

Hattie, J., Biggs, J., \&amp; Purdue, N. (1996). Effects of learning skills interventions o student learning: A meta-analysis. Review of Educational Research, 66(2), 99-136.

Henderickson, J. M. (1978). Error correction inforeign language teaching: Recenttheory, research and practice. The Modern Language Journal, 62(8),

387-398.

Izumi, S., \&amp; Bigelow, M. (2001).Methodological and theoretical issues in testing the effects of focus on form. TESOL Quarterly, 35, 181-189.

Kepner, C. G. (1991). An experiment in the relationship of types of written feedback the development of second language writing skills. Modern Language Journal,75, $\quad 305-$ 313.

Kowal, M., \&amp; Swain, M. (1994). Using collaborative language production tasks to promote students' language awareness. Language Awareness, 3, 73-93.

Krashen, S. (1982). Principles and practice in second language acquisition, Oxford: Pergamon.

Krashen, S. (1985). The input hypothesis: Issues and implications. New York Longman.

Kulhavy, R. W. (1977). Feedback in written instruction. Review of Educational Research, 47(2), 211-232.

Lalande, J. F. (1982). Reducing composition errors: An experiment. Modern Language Journal, 66, 140-149.

Lightbown, P., \&amp; Spada, N. (1994). An innovative program for primary ESL in Quebec. TESOL Quarterly, 28, 563-573.

Loewen, S. (2006). The occurrence and effectiveness of incidental focus on form in meaningfocused ESL lessons, (Unpublished Doctoral Thesis). The University of Auckland, Auckland, New Zealand.

Long, M. H. (1996). The role of the Linguistic Environment in Second Language Acquisition. W. C. Ritchie, \&amp; T. K. Bhatia (Eds.), Handbook of Second Language Acquisition. San Diego, CA: Academic Press. 
Lyster, R. (2004a). Research on form-focused instruction in immersion classrooms: Implications for theory and practice. French Language Studies, 14, 321-341.

Lyster, R. (2004b). Differential effects of prompts and recasts in form-focused instruction. Studies in Second Language Acquisition, 26, 399-432.

MacKey, A., Gass, S., \&amp; McDonough, K. (2003). How do learners perceive implicit negative feedback? Studies in Second Language Acquisition, 22, 471-497.

Philp, J. (2003). Constraints on "noticing the gap": Non-native speakers' noticing of recasts in NS-NNS interaction. Studies in Second Language Acquisition, 25, 99-126.

Pica, T., Young, R., \&amp; Doughty, C. (1998). The impact of interaction on comprehension. TESOL Quarterly, 21, 737-758.

Polio, C., Fleck, C., \&amp; Leder, N. (1998). If I only had more time: ESL learners' changes in linguistic accuracy ones say revisions. Journal of Second Language Writing, 7, 43-68.

Pressey, S. L. (1926). A simple device which gives tests and scores- and teaches. School and Society, 23, 373-376.

Robb, T., Ross, S., \&amp; Shortreed, I. (1986). Salience of feedback on error and its effecton EFL writing quality. TESOL Quarterly, 20, 83-93.

Robinson, P. (1995). Review article: Attention, memory and the "noticing" hypothesis. Language learning, 45, 283-331.

Swales, J. M. (1990). Genre analysis: English in Academic and Research Setting. Cambridge: Cambridge University Press.

Schmidt, R. (1995). Attention and awareness in foreign language learning. Honolulu, HI: University of Hawaii Press.

Schwartz, B. (1993). On explicit and negative data effecting and affecting competence and linguistic behavior. Studies in Second Language Acquisition, 15, 147-163.

Semke, H. (1984). The effects of the red pen. Foreign Language Annals, 17, 195-202.

Swain, M. (1995). Three Functions of Output in Second Language Learning. Principles and Practice in Applied Linguistics: Studies in Honor of H. G.

Truscott, J. (1996). The case against grammar correction in L2 writing classes. Language Learning, 46, 327-369.

Truscott, J. (1999). The case for "The case against grammar correction in L2 writing classes": A response to Ferris. Journal of Second Language Writing, 8(2), 111-122. 
White, L. (1987). Against comprehensible input: The input hypothesis and the development of L2 competence. Applied Linguistics, 8, 95-110.

Zamel, V. (1985). Responding to student writing. TESOL Quarterly 19:79-102 